\title{
The importance of social capital in the community to meet the needs of a family with a disabled child
}

\author{
Andrea Banovcinova* \\ Trnava University in Trnava, Trnava, Slovakia
}

\begin{abstract}
The birth, education and care of a disabled child can negatively affect not only the life and functioning of individual members but also the family as a whole. An important role in assisting and supporting families with disabled children can be played by the community and its social capital, including both formal and informal social networks and the sources of support, the relationships that families have built up. The aim of the research was to find out how the parents of a child with disabilities reflect the importance of the community for their family, with an emphasis on meeting the child's needs. A qualitative research strategy has been used to achieve the goal. The method of data collection was a semi-structured interview. The research file was made up of parents of children with disabilities. The results highlight the importance of an informal social network for the family, which includes a wider family, organizations operating in the third sector to help children with disabilities and their families. One of the most significant obstacles perceived by parents is the poor spatial availability of the organization, which is particularly evident in the rural environment, and also poor awareness of the possibilities of helping and supporting the family. From formal resources, parents particularly perceived the importance of doctors and medical staff.
\end{abstract}

\section{Introduction}

The needs of people with special needs are of interest to many professionals. Samuel, Rillotta and Brown [1] draw attention to the fact that while in the past the emphasis was primarily on meeting the individual needs of individuals with specific needs, regardless of their family and eco-social contexts, there is a change in this direction. The goal has been to support people with disabilities in their family environment. This trend is also reflected in the organization of services to help and care for a child with disability. According to King, Teplicky, King, Rosenbaum [2], a family-oriented philosophy of care is based on the belief that every family is unique, parents know their children best and also want the best for them. An important premise in this concept is the fact that the optimum functioning of the child depends on the supporting context of the family and community. Family support is recognized as both a style of work and a set of activities, which reinforce positive informal social networks through integrated programs. These programs combine statutory, voluntary, community and private services and are generally provided to families within their own homes and communities. The primary focus of these services is on early intervention aiming to promote and protect the health, well-being and rights of children and their families [3]. Therefore, the support

\footnotetext{
* Corresponding author: banovcinova.a@gmail.com
}

(C) The Authors, published by EDP Sciences. This is an Open Access article distributed under the terms of the Creative Commons Attribution License 4.0 (http://creativecommons.org/licenses/by/4.0/). 
from the wider family and community can be a significant factor in meeting the needs of the family with a disabled child and can favourably affect the quality of life of the family. The key role in fulfilling the needs of the children with disabilities as well as their families is played by the capital they have in the community they live in. Hancock [4] points out that putting people at the heart of community development, and putting human and community development at the heart of public policy and societal governance, needs to become a priority. Building community capital may involve the use of a range of community assets and is argued to have the potential to benefit communities as a whole while providing personal benefits for individuals and families. Among the results of such activities could be higher levels of trust and community participation, greater personal independence, and reduced social isolation [5]. On the other hand, as Bubolz [6] points out, the family plays an important role in building community capital, investing in the health, education, values and skills of its members to enable them to play productive roles in society. Human capital is essential for building economic, physical and social capital. Hancock [4] in his models, integrating the four capitals, emphasizes that (1) human development is the product of the interaction of social, economic and built capital within the context of natural capital; (2) Conceptually, the stronger is integration (overlap) in the development of social, economic and built capital, the greater is the level of human capital; (3) Some balance is needed between all these forms of capital in particular building one form of capital by depleting other forms of capital is not a viable strategy; (4) The combination of these forms of capital cannot exceed the natural capital (ecosystem health and integrity, resource sustainability, life support systems, carrying capacity).

\section{Methodology}

Childcare with specific needs puts increased demands on the family. The birth of a disabled child often brings specific needs for the family. Their lack of saturation can have a direct effect on increasing the stress and burden of parents, other family members and the child itself, which can result in a disruption of family functioning. Family members, however, often fail to fully meet these needs themselves and rely on help from the institution as well as communities. Understanding the needs of the family with a disabled child and their specifics is therefore a prerequisite for the effectiveness of family and child-specific intervention. For this reason, the identification of needs, the extent and the possibilities of their fulfilment, as well as the possibility to help them with their family, community and state fulfilment is the subject of the study of several experts. The level at which a family can meet the needs of their members depends to large extent on the support provided by the environment and the community they live in. This can be a significant source of different forms of support. The aim of the research was to find out how parents of a child with disabilities reflect the importance of the community for their family, with an emphasis on meeting the needs of the child.

A qualitative research strategy was used to achieve the goal. We used a semi-structured interview to collect data, and composing the areas of the interview, we used the model of community capital, as understood by Hancock [4]. According to him, community capital includes five forms of capital - natural, economic, social, built, and human capital. The following research tasks have emerged in meeting the research objective: (1) identify the main needs of families with disabled children; (2) identify opportunities for community capital towards families with disabled children; (3) to find out the perception of the community's contribution from the perspective of the parents of a disabled child. 


\subsection{Participants}

Deliberate selection was used to assemble the research sample. Due to our research goal, the sample in our research was made up of mothers of children with specific needs. The group consisted of 9 women (Average Age 36.83). All parents included in our research are parents of a disabled child. The condition for inclusion in the research group was that parents take care of the child personally at home.

\subsection{Results and discussion}

Basing on data analysis, we identified several areas that parents of children with disabilities consider as significant in terms of meeting the needs of the family and its individual members.

A very important topic for families with a disabled child with special needs is the economic area. Our research also confirmed this fact - financial needs reached the second highest average score. Childbirth is a social event that often brings increased financial demands on the family. On the one hand, the family loses one income from their work when their mother enters maternity leave. On the other hand, the costs associated with meeting the needs of the child are rising. In a family with a child with specific needs, the situation is more demanding since beyond the basic needs of the family, the family must also meet the needs of the child's diagnosis. According to parents' statements, assistance from the state often does not reach the level of real costs. Our participants' testimonies have shown that financial issues relate mainly to the needs of their affected child. On the one hand, they perceive the state's efforts to encourage them to take care of the child, but on the other hand, they perceive the way of support as inadequate (Claim to devices not reflecting the needs of the child). This finding is also proven by the statement of $\mathrm{P} 1$ : “... well... what is reimbursed by the insurance company I do not know how I could say it correctly... but, for example, those planks, they do not fulfil the function... they are overpaid by the insurance company, but they do not fulfil the function of pulling and balancing the tendons... they just make you a cast of that curvy leg and you put the curved leg in that curved splint and she gets you more nasty... you see, so I had to use... buy planks that are with frames with pull-in Velcro fasteners, and you can pull it off and you actually put it in balance... we had to buy it...". Similar experiences have also been described by Probant P2, which stated “... For example, it was paradoxical, it was absolute nonsense that you were entitled to benefits in the Office of Labour, Social Affairs and Family, or what kind of fund there is, but at first you had to choose to order the car through a health insurance company, which absolutely does not suit you, is heavy and robust, just to meet the law that you have requested a voucher, and then you are entitled to a post from the employment office to buy a car or something that takes off the child without difficulty... so I used it, and I bought a tricycle with the help of one foundation and we paid the rest..." ". To have appropriate equipment that helps in activities of daily living is also among key factors promoting families' wellbeing [7].

Economic functioning is associated with the financial capital that Hancock [4] describes as financial resources including savings, credit, and income from employment, trade and remittances.

With regard to economic issues, inability to be employed all mothers perceive as a negative factor. As one of the reasons, they pointed out the lack of adequate and affordable childcare. They mentioned also the lack of readiness, or even reluctance, on the part of educational institutions to accept a child with specific needs. (P2) "So ... they refuse to give an assistant for me, to take a part of my income, and I could work four hours a week or how it 
is, just... I cannot work... so I could, but it'll take some amount of money for the caregiver, so I'm absolutely not able to pay to go somewhere for half-time ... yes, it would be nice if they gave an assistant to the child and I could do some jobs ... " Sloper and Beresford [7] point to the fact that regardless of the tense economic situation in families with a disabled child, paid work is not a potential solution for care giving parents. Many parents reported significant financial hardship associated with their child's disease and ongoing care requirements [10]. The child's care needs multiple appointments with healthcare professionals, and the lack of childcare affects parents' ability to work. Lewis et al. [8], basing on the experience of mothers with a child with disabilities, state that the low level of participation of mothers with disabled children in labour force is a consequence of the inherent ideological and structural barriers these women face. Shearn and Todd [9] also came to similar conclusions. According to their findings, the lack of employability has led to isolation, lack of fulfilment, and low self-esteem. Similar conclusions have also been made in analyzing the testimony of our participants. Inability to work, at least on a part-time basis, is not only associated with the inability to improve the economic situation of their family. Above all, it is associated with the feeling of isolation since they are attached to the home and the child being cared for, and the impossibility of self-realization. (P4: "I would go to work because this is also exhausting for me. One needs some change already, and even a son needs some authority, because we can afford a little bit... so he tries").

Streamlining of the benefits system, integration both within and between health, education and social services, increased flexibility in the workplace, and dialogue and co-ordination between all of these elements, may go some way to providing the support these mothers need [8].

The second area that seemed to us important from interviews with parents was the area of information. Just enough objective information can help the family to understand the situation related to finding out that a child who is expecting birth or who is already born has a disability and to determine a particular diagnosis or diagnoses. The terms or diagnoses with which parents suddenly meet are often new to them. Pelentsov et al. [10] state that one of the most common cited informational need concerns the level of knowledge and understanding by health professionals. Parents voiced frustration by the lack of knowledge and experience demonstrated by health professionals associated with their child's disease. Poor communication and inability to provide parents with a comprehensive prognosis for them and their child were a constant source of concern for parents.

The results of our research have shown that the primary source of information on the diagnosis and condition of the child usually is the family doctor, whether it is a general practitioner or a specialist, whose care the child is gradually receiving. Our research participants mentioned a physician as an important source of information, e.g. mother P5: "... but we were in shock because we did not know what it was. Of course, when a person does not know, so the ignorance can kill .. . but I was looking for it, I asked ... when we went to the sanatorium, so the nurses, doctors, I got information from them ... because I did not know what to do.".

However, participants were aware of the lack of information on the prognosis of the child and on the normal functioning of children with a problematic diagnosis. This information had to be looked for by parents themselves, or turned to organizations working in the third sector. For example, the participant P2 said: "I did not know about the diagnosis absolutely anything... I was looking on the internet ... it was a time when I did not have my computer or internet access ... a very good friend helped me so much at the time. When I needed to verify something, I ran to use her computer ... ", and also participant P6: "I myself was looking for information and I consulted... I found myself a doctor in Brno and I called to various experts. .". 
A more detailed analysis of maternal testimonies, looking after a child with specific needs, has revealed a number of areas in which the lack of information exists. Probants have expressed the need for more detailed information on the services that their child could use in the current time or in the future. (P8: "whether there is anything else in the city for a son ... I do not know about anything, I do not think there's anything going to work here if he's still small ... but I hope that something will also be found in the course of time..."). Similar findings in his study also came from Huus et al., who found that most commonly parents' needs concerned information, especially regarding the support the child or family may expect as the child gets older, as well as regarding current support opportunities.

As our findings show, the problem is not only the lack of knowledge of possible sources of help and services in the community, but also the withdrawal of access to information by representatives of the authorities. It is our support for awareness and the supply of families with a child with specific needs, which is, from our point of view, only one of the most important possibilities for the community to help these families. Huus et al. [11]point to the fact, that parents who report having appropriate knowledge of child's development, child's impairment, and available support resources are more likely to exhibit stronger self-efficacy and to perceive greater control over the services needed or required. Parental self-efficacy refers to how confident the parents feel in their ability to handle child-related problems. Our participants often reflected negative experiences and inadequate staff awareness, which may indicate, on the one hand, the failure of the human factor (due to weak motivation or burnout in the Office's staff), but, on the other hand, it may indicate an inadequate system setting. In relation to the provision of information about services and claims, mother P4 said: "If I do not identify myself and find out what it means in their decisions and what I claim, I do not do anything in my life, because there is absolutely no support there. It is true they write the decision so that one does not understand it, they probably must do it by law, I understand it, but a little different approach would fit there... ".

The area that has proven to be completely inadequate in our research is an area of parenting information and counselling. Bailey et al. [11] highlight that specific needs of these families often relate to information and skills regarding how to handle behavioural problems and to adapt the home environment to the child's needs. Participants expressed the need to obtain information and advice on the development of their own parental skills and abilities as well as on their survival. However, this information was reported as inaccessible. This finding is evident, for example, from Mother P4's statement: “... I think the options for the child are rather good. There are doctors- specialists, different centres, school, ... but what I think is a bit forgotten is just the parents who take care of their children every day ... I myself sometimes need advice, for example, about how to handle the behaviour of my child. Sometimes I have problems, especially when it is difficult to distinguish which behaviour of the teenager is the manifestation of his illness and what is just clenched, and then sometimes I doubt whether my education is right." An interesting finding in our research was that although parents pointed out the lack of access to information and the need to find the information by themselves, their answers showed that they relied primarily on doctors, professionals and the Internet. From the point of view of the community, organizations operating within the third sector, as well as parents themselves, who have experience of taking care of the child through misconduct can be an important source of information. However, our participants did not feel the need to communicate with self-help or support groups. Similarly, Beresford [12] identifies support groups operating in the third sector as a valuable source of information.

The birth of a child with disabilities affects the functioning of not only the family as the whole, but also affects the life of each family member in a different way. Particularly significant influence falls on one of the parents - the child's caretaker. Qualitative parental 
research has revealed that those parents who have taken care of a child with specific needs often feel loneliness and some kind of isolation. Similar findings have also been found by Pelents et al [10], which state that social isolation, loneliness and feeling disconnected because of their child's disease and their caring routines were common issues cited by parents. Parents felt that their social life was lacking, there was a loss of freedom, and they longed for more spontaneity. Implications are not only to the individual, however. Stress and exhaustion may lead to increased health care resources being devoted to the caregiver as well as to the patient and may exacerbate family's destabilization and impoverishment. These are concerns not only for individuals and families but also for the larger society [13].

The results of our research have shown similar experiences in our probancy. For example, P2 states: "well ... basically we cannot go for the last two or three years, for example, on vacation ... the son has begun to be very defiant and he can make it known if he does not want ... so it's easier for us to go to him ... we have no one, who would take care of us so that we could go somewhere like this ... and this is a problem ... because I cannot ask my friend who has her family and children to come to look after my son, because I want to go somewhere. No..." In the life of the family, informal social networks that are available to individual members also play an important role. These networks can include, for example, a wider family, friends, as well as neighbouring communities. Our findings show that the participants perceive friends as a source of emotional support in particular. Participant P4 said: "my support was clearly a husband and an older son ... me and my husband, we always rely only on ourselves ... and then my friends ... when I needed something ..." An example of help and support in the community is also found in the P6 probation report: "our surroundings are great..., for example, our neighbour. We have a senior neighbour, a retiree, and she has also helped me a lot ... if I needed it, she would cradle him when I needed to go to school with my elder son, she has always been helpful, which is really great help, so I am very grateful ... again when she needs something my husband will repair it." We find it interesting to note that participants have perceived the problem of adopting a child's diagnosis by grandparents $(P 2:$ “... my parents did not accept my son, they could not reconcile with that..."). As a result, in these problems the family is an important source of support. They also perceive some helplessness in building up the acceptance and acceptance of the child by old parents. Vadasy et al. [14] point to the fact that the role of grandparents is often overlooked, but they often have resources that can strengthen the family. Findler [15] also reached similar conclusions. In her research grandparents, especially maternal grandmothers, were highly ranked in comparison with other support providers, and a clear hierarchy was revealed and they were perceived to be the most important figures providing more emotional than instrumental support and received the highest score in terms of satisfaction from support.

\section{Conclusion}

The community plays an important role in supporting the functioning of the family with a child with disabilities and meeting the needs of both the child and other members. Chenoweth and Stehlik [16], however, point out that people with disabilities and their families have largely been excluded from the broader social capital debate, and that social capital thinking has had little influence on efforts to achieve inclusion of people with disabilities into community life. The results of our research show that from the point of view of the family with a disabled child, economic, social and human capital play the most important role. Not only knowing the functioning of the community and its individual components, but also its possible contribution to the family and the disabled child is important from the point of view of helping professions. Based on our research, we see the need for increased emphasis on 
meeting the needs of both the child and the parents who are the primary caregivers, as well as building a family relationship with the wider environment.

This paper was prepared as part of the project APVV-14-0646 "Analysis of the social service in the area of early intervention in Slovakia".

\section{References}

[1] P.S. Samuel, F. Rillotta, I. Brown, J. Intellect. Disability Res. 56, 1-16 (2012)

[2] S. King, R. Teplicky, G. King, P. Rosenbaum, Family-Centered Service for Children with Cerebral Palsy and Their Families: A Review of the Literature, Seminars in pediatric neurology 11, 78-86 (2004)

[3] P. Dolan, J. Canavan, J. Pinkerton, Family Support as Reflective Practice (London, Jessica Kingsley Publishers, 2006), p. 304

[4] T. Hancock, Act Locally: Community-based population health promotion (2009). Available: https://sencanada.ca/content/sen/Committee/402/popu/rep/ appendixBjun09-e.pdf

[5] M. Knapp, A. Bauer, M. Perkins, T. Snell, Commun. Dev. J. 48(2), 313-331 (2012)

[6] M.M. Bubolz, J. Socio-Econo. 30(2), 129-131 (2001)

[7] T. Sloper, B. Beresford, BMJ 333(7575), 928-929 (2006)

[8] S. Lewis, C. Kagan, P. Heaton, M. Cranshaw, Economic and Psychological Benefits from Employment: The experiences and perspectives of mothers of disabled children, Disability and Society 14(4), 561-575 (1999)

[9] J. Shearn, S. Todd, J. Appl. Res. Intellect. Disabilities 13(3), 109-131 (2000)

[10] L.J. Pelentsov, et al., Disability Health J. 8, 475-491 (2015)

[11] K. Huus, L.M. Olsson, A.E.E. Andersson, M. Granlund, L. Augustine, Scandinavian J. Disability Res. 19(4), 307-317 (2017)

[12] B. Beresford, The Needs of Disabled Children and Their Families. A National Survey (Joseph Rowntree Foundation, York, 1995)

[13] P.S. Arno, C. Levine, M.M. Memmott, The Economic Value of Informal Caregiving, Health Affairs 18(2), 183-188 (1999)

[14] P.F. Vadasy, R.R. Fewell, D.J. Meyer, J. Division Early Childhood 10(1), 36-44 (1986)

[15] L.S. Findler, The Role of Grandparents in the Social Support System of Mothers of Children with a Physical Disability, Families in Society 81(4), 370-381 (2000)

[16] L. Chenoweth, D. Stehlik, Int. J. Inclusive Edu. 8(1), 59-72 (2004) 